TP Periodica Polytechnica

Mechanical Engineering

60(4), pp. 203-208, 2016

DOI: 10.3311/PPme.8684

Creative Commons Attribution (i)

RESEARCH ARTICLE

\section{Back Propagation Neural Network for Prediction of Some Shell Moulding Parameters}

\author{
Ramachandran Manickam ${ }^{1 *}$
}

Received 16 October 2015; accepted after revision 13 July 2016

\begin{abstract}
The present study has used an ANN to predict shell molding performances - permeability number and transverse strengthof sand moulds employed in hot metal casting. A back propagation ANN is used. This study utilized actual experimental data in which input conditions - CaCo3\%, MnO3\%, Dwell time and temperature - had been varied and the corresponding resulting performances were recorded. This data was used to both train and validate the ANN with the eventual objective of identifying optimum input conditions that would deliver desirable moulding performance output - the two targeted shell molding properties. The investigation used MATLAB 7.0 while the ANN's training and validation steps empirically varied learning rate, momentum rate, the number of hidden layers and the number of hidden neurons in each layer. The trained neural network was observed to be capable of predicting the output within 10\% error range of their corresponding observed values.
\end{abstract}

\section{Keywords}

shell moulding, Back Propagation Neural Network

\footnotetext{
${ }^{1}$ Department of Mechanical Engineering,

Mukesh Patel School of Technology Management Engineering,

Narsee Monjee Institute of Management Studies, Maharashtra, India

*Corresponding author, e-mail: sweetestchandran@gmail.com
}

\section{Introduction}

Shell moulding system is an improved process of sand casting which gives improved surface finish, better dimensional accuracy, good tolerances and higher production rate than is obtained by sand mould casting. Artificial Neural Network (ANN) is one application of Artificial Intelligence that has achieved considerable success in recent years in modeling multifactor processes and opened a new dimension for optimizing complex systems in scientific research and business applications $[1,2]$. In this study an evaluation system for the surface defects of casting was established to quantify surface defects, and ANN was designed and used to help generalize the relationship between surface defects, and process parameters of die-casting, such as molding temperature, pouring temperature, and injection velocity $[3,4]$. Metal forming is the important manufacturing processes in present day manufacturing which is highly dependent on process settings $[5,6]$. In earlier application the neural network was trained with data collected from an actual cast iron foundry operation [7, 8]. After the training was over, the set of inputs of new castings that were to be made was fed to the network for the network to predict the percentage defectives. The actual experimental outputs were found to be in good agreement with the predicted values [9, 10]. Back propagation (BP) neural networks have been applied to real world problems that are too complex to be solved by conventional technologies $[11,12]$. BP neural network is a generalization of the delta rule used for training multi-layer feed forward neural network with nonlinear units $[13,14]$. These investigations were aimed at the selection of the proper kind of a neural network for prediction a sand moistness on the bases of certain moulding sand properties such as: permeability, compatibility and friability $[15,16]$. In these studies these parameters - determined as sand moistness functions - were introduced as initial parameters $[17,18]$. One of the potential applications of backpropagation ANN for selection of a Stereo lithography apparatus (SLA) machine $[19,20]$. The present study has aimed at predicting shell moulding performance using the ANN. 


\section{Methodology}

An artificial neural network is an information processing system in which the elements called neurons calculate the information required and produce signals. The signals are then communicated by means of connecting links. The links feature associated weight, which is then multiplied by the incoming signal in a typical neural net. The produced signal is then obtained by applying activations to the net input [21,22]. An artificial neuron network is characterized by the following features:

- Architecture (Connection between Neurons)

- Training or Learning (Determining Weights on the Connections)

- Activation Function (to minimize errors in modeling)

After establishing the basis of neural nets, one move to the practical networks, their applications and how they are trained. There are several algorithms available now to construct an artificial neural network presently we used the back-propagation (BP) training algorithm. In the Back-propagation network, initially the weights are calculated arbitrarily. Accordingly, the outputs are also product randomly. However, the outputs so calculated are compared with the actual/desired outputs by the network and the error is conveyed to the initial layer, this "back propagation" process results in correction of the weights.

The Transfer function used within the nodes in this back-propagation network is the 'sigmoid function'. The network begins calculating its output values by passing the weighted inputs to the nodes in the first layer. The resulting node outputs of that layer are passed on, through an altogether different set of weights, to the second layer, and so on until the nodes of the output layer compute the final outputs. In this case, each input parameter (s) and output parameter $(t)$ is normalized. After training is over the network simulates the value to be tested. The simulated or assumed outputs and actual outputs that are in normalized state are then altered back to original values by post processing. Denormalizing the predicted values is done by the formula:

$$
Y(i)=[x(i)-c] / e
$$

$Y(i)=$ nth value of normalize output

$X(i)=$ Denormalize output value

$c=$ min. value of actual value

$\mathrm{e}=$ difference $\mathrm{b} / \mathrm{w}$ minimum and maximum values of actual value

Figure 1 shows the flow chart of proposed methodology of this study. In this study, a BP artificial neural network was used to model the parameters of shell moulding. It was found that the trained network has very good forecasting ability. Furthermore, the trained neural network was later employed as an objective function to optimize the processes. The first step was to collect the data and normalize that data between $0-1$ values by coding on Matlab 7.0. In this work the total no. of samples used was sixteen and out of 16,10 samples were used for training the network and 6 used for testing the network. Applying BPNN algorithm in Matlab 7.0 for training and testing data on the same network delivered the desired outputs. If there were any large errors in outputs, then we changed the parameters, The Architecture and The Activation functions.

\subsection{Artificial Neural Network (ANN)}

This study used a limited number of available physically conducted actual mold making experiments. It is well known that neural network has been designed to optimize single quality characteristics, but to consider several quality characteristics together in the selection of process parameters; modified neural network technique was used in Matlab 7.0. The data of shell moulding was taken from $[23,24]$. Their method applied the Taguchi for parameter prediction of shell moulding process. In this study input parameters were percentage of $\mathrm{CaCO}_{3}$, Percentage of $\mathrm{MnO}_{2}$, Dwell time, Temperature $\left({ }^{\circ} \mathrm{C}\right)$ and output (performance) parameters were permeability and Transverse Strength. Table 1 displays the actual data.

\subsection{Training and Testing of Network}

In this analysis ANN was used to anticipate two shell moulding performances - permeability number and transverse strength. Totally, sixteen samples of data were accumulated. The first 10 samples were used for training the network and the latter 6 samples were reserved solely for testing the accuracy and precession of the trained network. In the neural network programmed schedule, momentum rate was set as 0.9 and learning rate as 0.05 . The network architecture is then tried and tested with incrementing number of hidden neurons, but the one with single hidden layer as a comparison gave best results with an optimum training time. The programme was implemented using mat lab and the network assembled with the error tracking limit set at 1000 iterations. After training, the network was tested for its accuracy and precession. The input data parameters of the 10 samples that were not used in training the neural network were provided to the trained network and the network was asked to analyze the achievable outcomes. Table 1 thus shows the experimentally observed values listed for training and testing.

\section{Results and Discussion}

The predictions made by the back-propagation neural network are satisfactory in most of the cases. The network was trained with least possible error in order to have good predictions over the percentage of defective items produced. This particular training requires skill, trial and error approach to determine the activation functions and the hidden layer neurons. The network was trained with optimal conditions to give closer approach to the results. Figure 2-3 shows the training of inputs and the networks stop training after reaching the desired goal. Full set of inputs were passed through the neural network to compute the performance, each such pass is called an Epoch. 


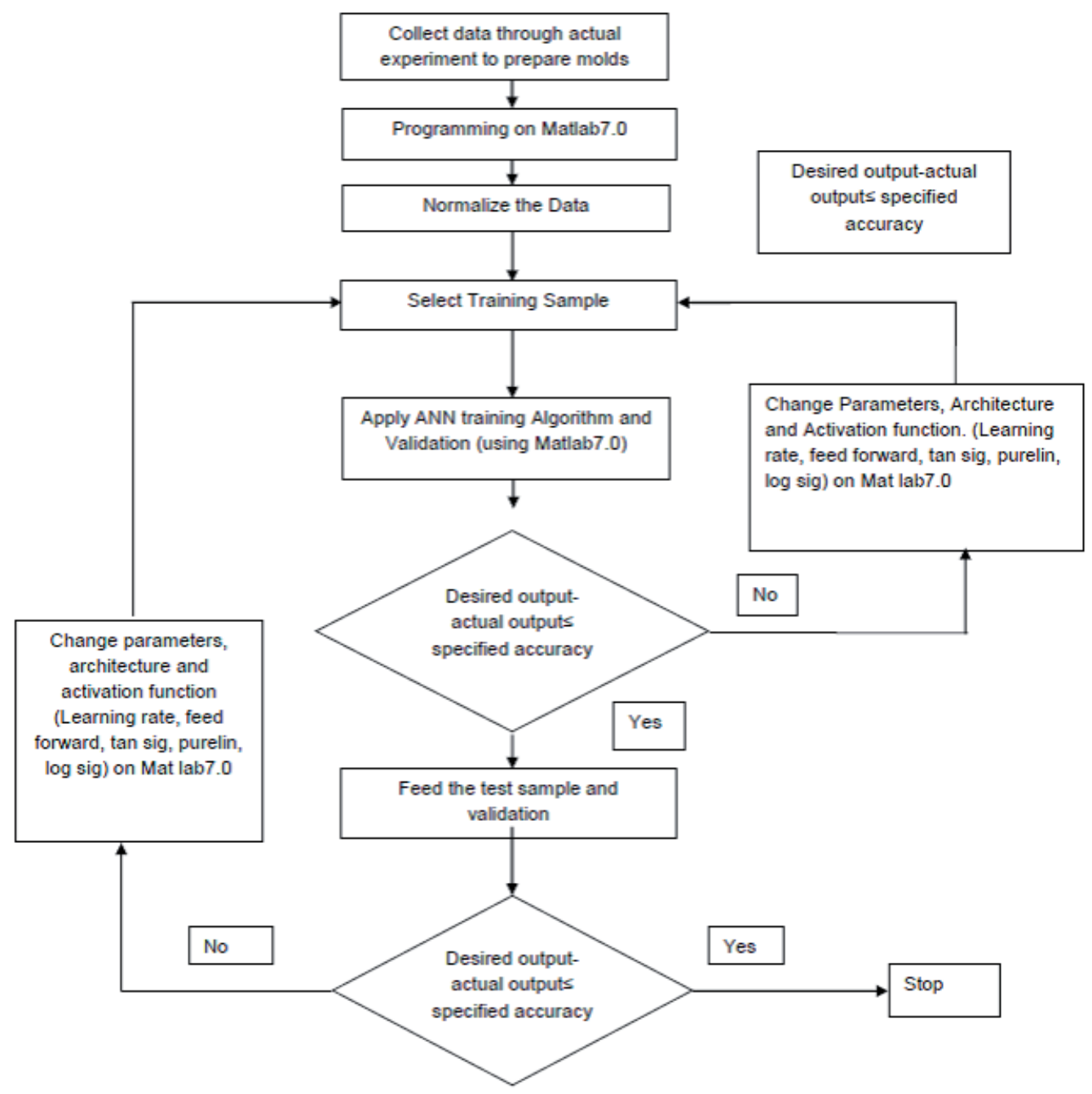

Fig. 1 Flow chart of Proposed Methodology

Table 1 Process Parameters and Actual mold performance from [25]

\begin{tabular}{lllllll}
\hline & \multicolumn{3}{c}{ INPUT PARAMETERS } & \multicolumn{2}{c}{ OUTPUT PARAMETERS } \\
\cline { 2 - 7 } Sl.No & $\% \mathrm{CaCO}_{3}$ & $\% \mathrm{MnO}_{2}$ & $\begin{array}{l}\text { Dwell Time } \\
(\text { minutes })\end{array}$ & $\begin{array}{l}\text { Temperature } \\
\left({ }^{\circ} \mathrm{c}\right)\end{array}$ & $\begin{array}{l}\text { Permeability } \\
\text { Number }\end{array}$ & $\begin{array}{l}\text { Transverse } \\
\text { Strength (Kpa) }\end{array}$ \\
\hline 1. & 2 & 2 & 1 & 300 & 125 & 150 \\
2. & 2 & 4 & 2 & 325 & 126 & 170 \\
3. & 2 & 6 & 3 & 350 & 150 & 200 \\
4. & 2 & 8 & 4 & 400 & 155 & 210 \\
5. & 4 & 2 & 2 & 350 & 100 & 350 \\
6. & 4 & 4 & 1 & 400 & 105 & 380 \\
7. & 4 & 6 & 4 & 300 & 120 & 420 \\
8. & 4 & 8 & 3 & 325 & 118 & 400 \\
9. & 6 & 2 & 3 & 400 & 60 & 390 \\
10. & 6 & 4 & 4 & 350 & 90 & 400 \\
11. & 6 & 6 & 1 & 300 & 75 & 205 \\
12. & 6 & 8 & 2 & 325 & 80 & 350 \\
13. & 8 & 2 & 4 & 325 & 55 & 275 \\
14. & 8 & 4 & 3 & 300 & 57 & 260 \\
15. & 8 & 6 & 2 & 400 & 75 & 250 \\
16. & 8 & 8 & 1 & 950 & 90 & 135 \\
\hline
\end{tabular}




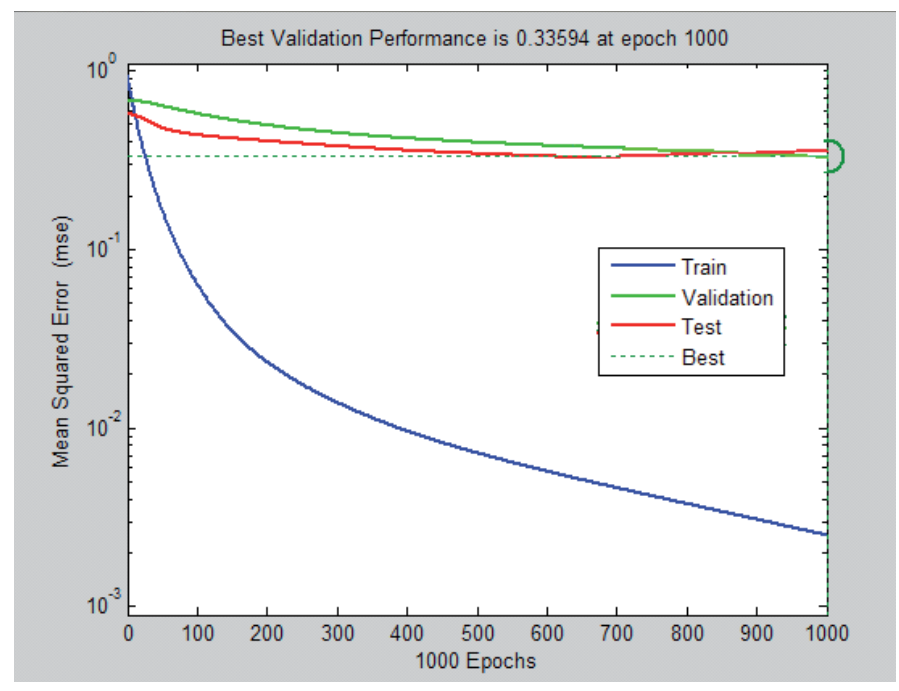

After reaching the desired least error, the network is then simulated with testing data inputs to calculate the accuracy of the neural network model. The output of the neural network is found to be in good agreement with the actual testing data output. Table 4 shows the Comparison of error b/w Transfer Functions. Table 3 displays Simulation results of modeling of shell moulding process parameters using Ann on Matlab 7.0. There are three different transfer function was used. By this process, result can be compared that which transfer function will give closer results. After simulation it is found that "log sig" transfer function is better. It gives much closer results and minimum error.

Fig. 2 Validation Performance Chart
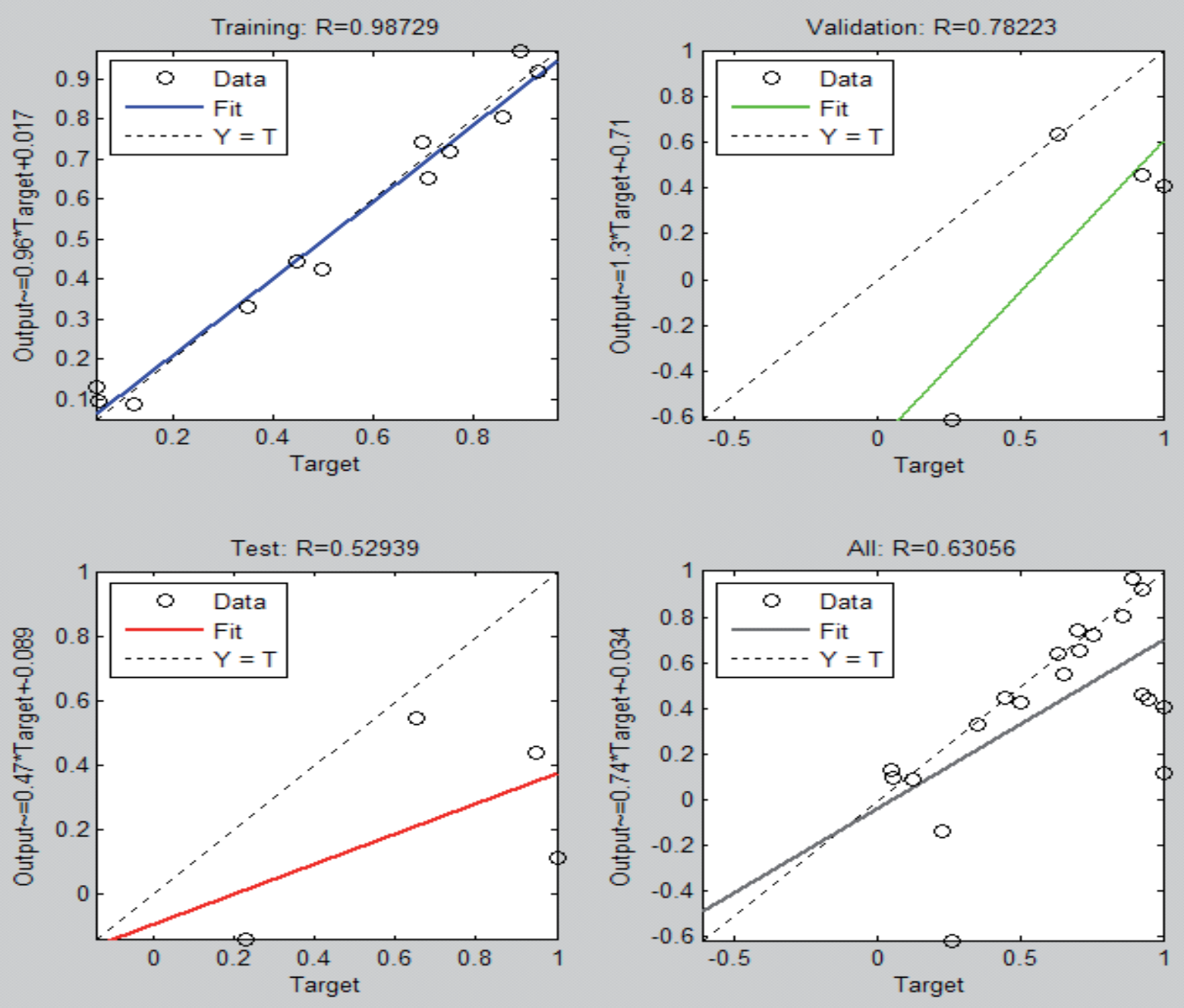

Fig. 3 Regression plot

Table 2 Predicted Error between parameters of Shell moulding

\begin{tabular}{llll}
\hline SI.No & Parameters & Training error (\%) & Testing error (\%) \\
\hline 1 & Permeability no. & $5.1 \%$ & $4.8 \%$ \\
2 & Transverse strength & $4.8 \%$ & $17 \%$ \\
\hline
\end{tabular}


Table 3 Simulation results of shell moulding process parameters

\begin{tabular}{|c|c|c|c|c|c|c|c|c|c|}
\hline \multirow{3}{*}{$\begin{array}{l}\text { SI. } \\
\text { No. }\end{array}$} & \multirow{3}{*}{$\begin{array}{l}\text { No. of Hidden } \\
\text { Layers }\end{array}$} & \multirow{3}{*}{$\begin{array}{l}\text { Transfer } \\
\text { functions }\end{array}$} & \multirow{3}{*}{\multicolumn{2}{|c|}{$\begin{array}{c}\text { No. of } \\
\text { Neurons }\end{array}$}} & \multirow{3}{*}{$\begin{array}{c}\text { Mean Square } \\
\text { Error }\end{array}$} & \multicolumn{4}{|c|}{ Average Values } \\
\hline & & & & & & \multicolumn{2}{|c|}{ Training } & \multicolumn{2}{|c|}{ Testing } \\
\hline & & & & & & Y1 & $\mathrm{Y} 2$ & $\mathrm{Y} 1$ & $\mathrm{Y} 2$ \\
\hline \multirow[t]{3}{*}{1.} & \multirow{3}{*}{ one } & \multirow{3}{*}{ 'traingd' } & \multicolumn{2}{|c|}{10} & 0.35 & 0.1228 & 0.2616 & 0.3694 & 1.0007 \\
\hline & & & \multicolumn{2}{|c|}{20} & 0.25 & 0.0494 & 0.0061 & 0.1487 & 0.7821 \\
\hline & & & \multicolumn{2}{|c|}{30} & 0.22 & 0.0965 & 0.0772 & 0.9452 & 0.9665 \\
\hline \multirow[t]{4}{*}{2.} & \multirow{4}{*}{ Two } & \multirow{4}{*}{ 'traingd' } & H1 & $\mathrm{H} 2$ & & & & & \\
\hline & & & 10 & 10 & 0.18 & 0.1911 & 0.0190 & 0.5625 & 0.6276 \\
\hline & & & 10 & 20 & 0.12 & 0.1347 & 0.2477 & 0.7654 & 1.5603 \\
\hline & & & 10 & 30 & 0.11 & 0.0897 & 0.9422 & 0.5196 & 0.9924 \\
\hline \multirow[t]{4}{*}{3.} & \multirow{4}{*}{ Two } & \multirow{4}{*}{ 'purelin' } & H1 & $\mathrm{H} 2$ & & & & & \\
\hline & & & 10 & 10 & 0.003 & 0.0179 & 0.1332 & 0.0989 & 1.7167 \\
\hline & & & 10 & 20 & 0.002 & 0.0269 & 0.0211 & 0.2008 & 1.3635 \\
\hline & & & 10 & 30 & 0.001 & 0.0657 & 0.2404 & 0.3459 & 1.3055 \\
\hline \multirow[t]{4}{*}{4.} & \multirow{4}{*}{ Two } & \multirow{4}{*}{ 'tansig' } & $\mathrm{H} 1$ & $\mathrm{H} 2$ & & & & & \\
\hline & & & 10 & 10 & 0.1 & 0.1878 & 0.0917 & 0.6092 & 0.8735 \\
\hline & & & 10 & 20 & 0.08 & 0.0448 & 0.1666 & 0.0085 & 0.8306 \\
\hline & & & 10 & 30 & 0.001 & 0 & 0 & 0.7003 & 0.9551 \\
\hline \multirow[t]{4}{*}{5.} & \multirow{4}{*}{ Two } & \multirow{4}{*}{ 'logsig' } & $\mathrm{H} 1$ & $\mathrm{H} 2$ & & & & & \\
\hline & & & 10 & 10 & 0.01 & 0.1293 & 0.1546 & 0.1707 & 0.3716 \\
\hline & & & 10 & 20 & 0.001 & 0.0338 & 0.0148 & 0.1969 & 0.5631 \\
\hline & & & 10 & 30 & 0.003 & 0.0379 & 0.1893 & 0.4064 & 0.2887 \\
\hline
\end{tabular}

Table 4 Comparison of Error between Transfer Functions

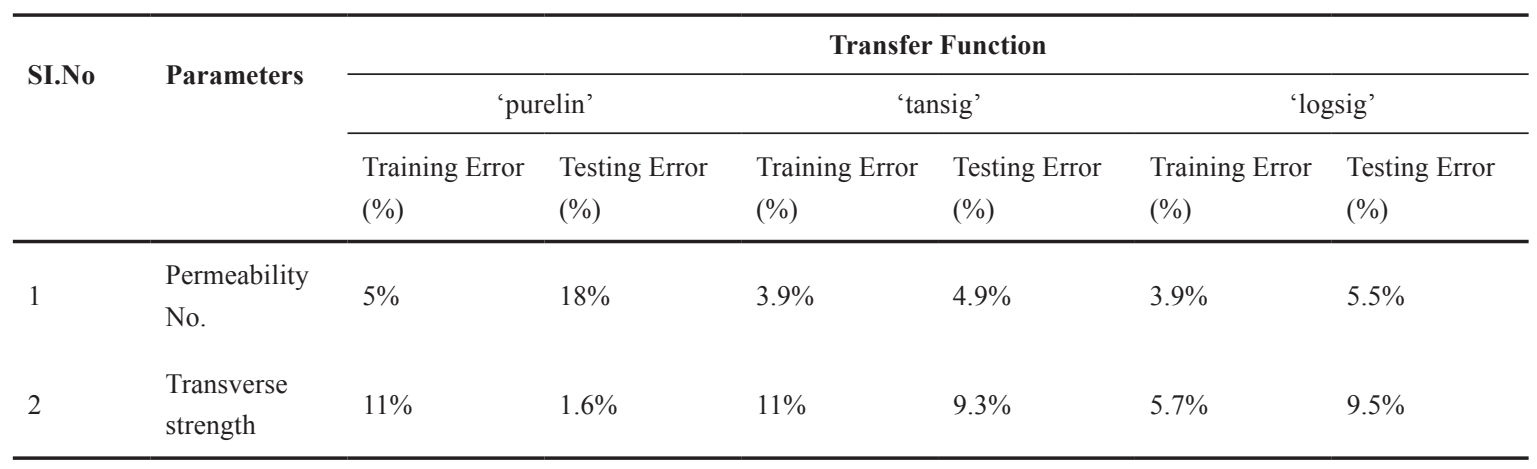

\section{Conclusion}

Artificial Neural Networks seem to be a very interesting IT tool to support sand preparation control processes employed in shell moulding. A great deal of investigation is generally required to find best selection of Shell Moulding parameters. In this study, the Back Propagation Neural Network is applied for prediction of sand properties for shell moulding process. Table 4 shows the comparison of error between various transfers functions, transfer function are 'purelin', 'tan sig', 'log sig'. Mean square error of training and testing data both are presented in this table. So, among these transfer functions 'log sig' gives the minimum error as compare to purelin and tan sigmoid. Training error for permeability no. is $3.9 \%$ and transverse strength is $5.7 \%$ and similarly error which comes from testing process, is $5.5 \%$ and $9.5 \%$ respectively. So, we can observe that in this case error comes under $10 \%$. But in case of 'purelin' training error is $5 \%$ and $11 \%$ respectively and testing error is $18 \%$ and $1.6 \%$ respectively. Here error is more than $10 \%$. And similarly, in the case of 'tan sig' it also gives error more that $10 \%$. Finally conclusion is that 'log sigmoid' transfer function is best as compare to pure linear and tan sigmoid. 


\section{References}

[1] Raj, H. K. , Sharma, R. S., Srivastava, S., Parvardhan, C. "Modeling of Manufacturing Processes with ANNs for Intelligent Manufacturing." International Journal of Machine Tools and Manufacture. 40(6), pp. 851868. 2000. DOI: $10.1016 / \mathrm{S} 0890-6955(99) 00094-2$

[2] Avila, C., Tsuji Y., Shiraishi, Y. "Crack Width Prediction of RC Structures by Artificial Neural Networks." In: Ribeiro, B., Albrecht, R. F., Dobnikar, A., Pearson, D. W., Steele, N. C. (eds.) Adaptive and Natural Computing Algorithms: Proceedings of the International Conference in Coimbra, Portugal, 2005, Springer Vienna, pp. 92-95. 2005.

DOI: 10.1007/3-211-27389-1_22

[3] Ozcelik, B., Erzurumlu, T. "Comparison of the warpage optimization in the plastic injection molding using ANOVA, neural network model and genetic algorithm." Journal of Materials Processing Technology. 171(3), pp. 437-445. 2006. DOI: 10.1016/j.jmatprotec.2005.04.120

[4] Guo, Z., Zhao, W., Lu, H., Wang, J. "Multi-step forecasting for wind speed using a modified EMD-based artificial neural network model." Renewable Energy. 37(1), 241-249. 2012. DOI: 10.1016/j.renene.2011.06.023

[5] Singh, R. "Investigating the effect of moulding sand properties on investment castings: a process capability study." Journal of Mechanical Science and Technology. 27(3), pp. 837-842. 2013.

DOI: $10.1007 / \mathrm{s} 12206-013-0107-\mathrm{x}$

[6] Spörrer, A. N. J., Altstädt, V. "Controlling morphology of injection molded structural foams by mold design and processing parameters." Journal of Cellular Plastics. 43(4-5), pp. 313-330. 2007. DOI: $10.1177 / 0021955 X 07079043$

[7] Singh, R., Mahajan, V. "Some Investigations on Hardness of Investment Casting Process after Advancements in Shell Moulding for Reduction in Cycle Time." Journal of The Institution of Engineers (India): Series C. 95(3), pp. 233-238. DOI: 10.1007/s40032-014-0121-5

[8] Chiang, K.-T., Chang, F.-P. "Application of grey-fuzzy logic on the optimal process design of an injection-molded part with a thin shell feature." International Communications in Heat and Mass Transfer. 33(1), pp. 94-101. 2006. DOI: 10.1016/j.icheatmasstransfer.2005.08.006

[9] Khedkar, S. S., Awari, G. K., Untawale S. P., Chaudhari S. "Investigation on Intelligent Fault Diagnosis System for Valve Casting Using ANN." VSRD International Journal of Technical \& Non-Technical Research. 2(2), pp. 58-63. 2011.

[10] Silver, H. "Neural Network in Electrical Engineering." In: Proceedings of the ASEE New England Section Annual Conference, 2006.

[11] Purohit, P., Ramachandran, M. "Selection of Flywheel Material using Multicriteria Decision Making Fuzzy Topsis." Indian Journal of Science and Technology. 8(33), pp. 1-5. 2015. DOI: $10.17485 / \mathrm{ijst} / 2015 / \mathrm{v} 8 \mathrm{i} 33 / 80028$

[12] Sulaiman, S., Hamouda, A. M. S. "Modeling of the Thermal History of the Sand Casting Process." Journal of Materials Processing Technology. 113(1-3), pp. 245-250. 2001. DOI: 10.1016/S0924-0136(01)00592-1
[13] Li ,L. K., Shao, S., Yiu, K.-F. C. "A New Optimization Algorithm for Single Hidden Layer Feedforward Neural Networks." Applied Soft Computing. 13(5), pp. 2857-2862. 2013. DOI: 10.1016/j.asoc.2012.04.034

[14] Krimpenis, A., Benardos, P. G., Vosniakos, G.-C., Koukouvitaki, A. "Simulation-based selection of optimum pressure die-casting process parameters using neural nets and genetic algorithms." The International Journal of Advanced Manufacturing Technology. 27(5), pp. 509-517. 2006. DOI: $10.1007 / \mathrm{s} 00170-004-2218-0$

[15] Jain, M., Ramachandran, M. "Buy/Make decision making framework for pump product development with multi criteria decision making." International Journal of Applied Engineering Research. 10(11), pp. 10486-10489.

[16] Rizvi, S. J. A., Bhatnagar, N. "Optimization of microcellular injection molding parameters." International Polymer Processing. 24(5), pp. 399405. 2009. DOI: $10.3139 / 217.2263$

[17] Tseng, W. J. "Statistical analysis of process parameters influencing dimensional control in ceramic injection moulding." Journal of Materials Processing Technology. 79(1-3), pp. 242-250. 1998.

DOI: 10.1016/S0924-0136(98)00019-3

[18] Yin, F., Mao, H., Hua, L. "A hybrid of back propagation neural network and genetic algorithm for optimization of injection molding process parameters." Materials \& Design. 32(6), pp. 3457-3464. 2011. DOI: 10.1016/j.matdes.2011.01.058

[19] Samanta, B., Al-Balushi, K. R. "Artificial neural network based fault diagnostics of rolling element bearings using time-domain features. $\mathrm{Me}$ chanical Systems and Signal Processing. 17(2), pp. 317-328. 2003. DOI: $10.1006 / \mathrm{mssp} .2001 .1462$

[20] Goh, A. T. C. "Back-propagation neural networks for modeling complex systems." Artificial Intelligence in Engineering. 9(3), pp. 143-151. 1995. DOI: 10.1016/0954-1810(94)00011-S

[21] Chen, H., Zeng, Z. "Deformation prediction of landslide based on improved back-propagation neural network." Cognitive Computation. 5(1), pp. 56-62. 2013. DOI: 10.1007/s12559-012-9148-1

[22] Attia, U. M., Alcock, J. R. "Fabrication of ceramic micro-scale hollow components by micro-powder injection moulding. Journal of the European Ceramic Society. 32(6), pp. 1199-1204. 2012. DOI: 10.1016/j.jeurceramsoc.2011.11.045

[23] Park, J. M., Kang, H. T. "Prediction of fatigue life for spot welds using back-propagation neural networks." Materials \& Design. 28(10), pp. 2577-2584. 2007. DOI: 10.1016/j.matdes.2006.10.014

[24] Karunakar, D. B., Datta, G. L. "Prevention of defects in castings using back propagation neural networks." The International Journal of Advanced Manufacturing Technology. 39(11), pp. 1111-1124. 2008. DOI: $10.1007 / \mathrm{s} 00170-007-1289-0$

[25] Satyanarayana, V .V., Reddy, G. M., Veladri, K. "Application of Modified Taguchi Method in process parameter selection of the Shell Moulding Process." Indian Foundry Journal. 53, p.10. 2007. 